\title{
Security Test of New Technology in View of Increased Performance of Oil Platforms Without Increasing Environmental Risks
}

\author{
E. M. Tanoh Boguy ${ }^{(凶)}$ and T. Chekushina \\ Department of Mineral Developing and Oil \& Gas Engineering, \\ Engineering Academy, RUDN University, Moscow, Russia \\ boguymartialeddy@gmail.com
}

\begin{abstract}
In this article, it will be important to note the context of the gradual depletion of existing fields, which are pushing to expand research and exploitation of new fossil fuel resources in order to meet the growing demand for fuel and, despite international regulations to combat global warming. Consequently, an increase in offshore platforms in global hydrocarbon production to compensate for the depletion of the earth's reserves is becoming a major problem for the oil industry. Given the financial unforeseenness that is represented, and the energy autonomy which is provided, marine exploitation has become a problem for states with a large sea area and, therefore, an environmental.
\end{abstract}

Keywords: Security test $\cdot$ New technology $\cdot$ Increased performance $\cdot$ Environmental risks

\section{Introduction}

The use of new reserves, in economically viable conditions depends on the available technologies. The development of deep and ultra-deep offshores requires considerable research and development efforts. Progress has also been made in managing the multiple risks associated with this activity. A disaster like «Deepwater Horizon» led to a detailed analysis and sharing of findings by industry experts.

Despite the security rules on the platforms, in fact, some major incidents are revealed, the causes of which are multifactorial in nature and which have dire consequences for both humans and the environment.

Legislation forces organizations to take responsibility for dealing with disasters, which has been developed over time and in different ways in different countries.

Our analysis of how environmental risks are taken into account by various subjects and offers development prospects to ensure better safety of offshore activities.

\section{Methods and Approaches}

Some of the accidents at oil rigs, such as the Deepwater Horizon, in the spring of 2010 caused a shock wave in their magnitude and severity that convinced that such accidents could occur. In fact, some states have taken steps to raise the level of security. In fact, 
some states have taken upon themselves the task of "solving the problem of providing security on the shelf." Global hydrocarbon production is becoming more and more offshore, accounting for more than $35 \%$ of oil and $19 \%$ of gas. Since the deposits are located at great depths, states and companies must develop the potential for their use, seeking to control the risks inherent in this activity carried out under extreme conditions. In order not to have restrictions in the conditions in which exploration, drilling and mining operations are carried out, by more and more complex and risky methods. In addition, oil companies are well aware of their interest in investing in the development of new technologies. This allows them to gain an industrial competitive advantage in strategic areas of deepwater exploitation. Significant progress has been made in managing the multiple risks inherent in offshore operations. Oil companies put prevention at the level of operating conditions.

\section{Results and Discussion}

Regardless of the achievements observed, it is obvious that the safety rules applied on the platforms guarantee greater efficiency than environmental protection, and that more and more risks are encountered. Increasing risks to humans and the environment is inextricably linked with the complexity of drilling operations. Working platforms continue to find solutions that completely avoid any potential risks in the protected areas. Advanced technology and security measures suggest that there is a clear improvement, but the limit between politically correct and pollution is quickly exceeded when it comes to such profits.

\section{Conclusions}

Finally, it is important to include risk management in determining policies, procedures and plans, as well as specific risk mitigation measures that will be taken to manage security risks. The environment is associated with all sorts of accidents, while drilling and operating the platform. The accident, which is a major problem for these exploitation will be a hydrocarbon spill, which is highly unlikely and will be limited to pumping oil and fuel stored on support vessels in the event of a tank failure or reloading pipe.

Open Access This chapter is licensed under the terms of the Creative Commons Attribution 4.0 International License (http://creativecommons.org/licenses/by/4.0/), which permits use, sharing, adaptation, distribution and reproduction in any medium or format, as long as you give appropriate credit to the original author(s) and the source, provide a link to the Creative Commons license and indicate if changes were made.

The images or other third party material in this chapter are included in the chapter's Creative Commons license, unless indicated otherwise in a credit line to the material. If material is not included in the chapter's Creative Commons license and your intended use is not permitted by statutory regulation or exceeds the permitted use, you will need to obtain permission directly from the copyright holder.

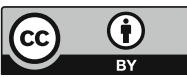

